\title{
Study of Yield Strength and Elongation Variations of Reinforcement Steel Bars (TMT bars) Manufactured Using Local Ingots
}

\author{
K.P.A.S. Perera and S.P. Guluwita
}

\begin{abstract}
Recycling of scrap steel to produce ribbed steel bars is a common practice followed in many countries. Selection of the best composition of ingredients for the melt is a huge challenge faced by the manufacturers in the scrap recycling industry. A major problem faced by them during the recycling process is the difficulty they have in controlling the levels of undesirable residual elements such as $\mathrm{Cu}, \mathrm{Ni}$, Sn, As, Cr, Mo, Pb, etc., that come with scraps. In SLS 375:2009 and BS 4449 Standards, the 'maximum percentage by mass' of residual elements is represented by the "Carbon Equivalent Value". Carbon Equivalent (CE) value is used to understand how different alloys and residual elements affect the strength of steel. In ingot casting, a good control of ladle treatment is required for the proper control of de-oxidation and de-sulphurisation chemicals and residuals. An extensive study was carried out by referring to the literature and benchmarking the best practices of several steel makers to improve the ingot casting process. In this paper, the results of the experimental investigation on the effects of alloying and residual elements on yield strength and elongation of TMT bars is presented.
\end{abstract}

The experimental study was focused on identifying the most suitable mixed proportion of ferrosilicon to ferro-silico-manganese, and the best controllable range of $\mathrm{CE}$ values to be used during melting to ensure that the products manufactured are consistent in quality. The quantities of the main alloying chemicals mixed together are changed to make the diluted percentage of manganese content in the bath solution to be $0.8 \%$ by mass. The ingots and TMT bar samples prepared were tested to see how the Carbon Equivalent value and the mixed proportion of alloying chemicals affect the yield strength and elongation of the finished bars. It was revealed that a consistent yield strength and elongation of each TMT bar of a set can be achieved by having the Carbon Equivalent value in the range $0.37<\mathrm{CE}<0.4 \%$ by mass and by mixing of ferro-silicon and ferro-silico-manganese ( $\mathrm{Si}: \mathrm{Mn}$ ) approximately in the proportion of $1: 4$.

Keywords: Thermo-Mechanically Treated (TMT) Bars, Carbon Equivalent (CE), Ferro-silicon, Ferrosilico-manganese, Yield Strength and Elongation

\section{Introduction}

Scrap recycling is an area that draws intense scientific attraction because of its ability to conserve earth's resources and energy and offer solutions to overcome environmental issues. Scrap recycling in the secondary steel making process plays a vital role in the production of ribbed steel bars. The main feed materials used in the secondary steel making process are scrap steel and direct reduced iron (DRI) or sponge iron. Secondary steel making is usually performed in ladles. The steel making process also includes alloy addition, de-oxidation, vacuum degassing, correction of inclusion chemistry, and homogenization. By controlling the ladle metallurgy effectively, high quality steel could be produced.
There are presently several ribbed steel bar manufacturers who do scrap recycling. Owing to various constraints, it has however become difficult for them to achieve consistent tensile properties especially properties like yield strength and elongation in the ribbed steel bars they manufacture. The product test report issued by the Materials Testing Laboratory of SLSI presented in Table 1 confirms this.

Mr. K.P.A.S. Perera, M.Sc. (Student), University of Moratuwa, B.Sc. (Sp) in Mathematics (Kelaniya), Dip. in Quality Management, ISO 9001 (QMS) Lead Auditor, Assistant Director, Sri Lanka Standards Institution (SLSI) Email:pramith@slsi.lk

Eng. S.P. Guluwita, B.Sc. Eng. Hons (Moratuwa), C. Eng., MIE (Sri Lanka), M.Sc. (Peradeniya), M.Phil. (Moratuwa), Senior Lecturer, Department of Materials Science and Engineering, University of Moratuwa. Email:sguluwita@uom.lk 
Table 1 - Test report of ribbed steel bars of size $12 \mathrm{~mm}$

\begin{tabular}{|c|c|c|c|c|c|c|}
\hline \multirow{3}{*}{ Parameter } & \multicolumn{5}{|c|}{ Steel grade RB 500} & \multirow{3}{*}{$\begin{array}{l}\text { SLS 375: } 2009 \\
\text { Standard } \\
\text { Specification } \\
\text { ( size } 12 \mathrm{~mm} \text { ) }\end{array}$} \\
\hline & \multicolumn{5}{|c|}{ Specimen number } & \\
\hline & 01 & 02 & 03 & 04 & 05 & \\
\hline 1. Mass per meter $(\mathrm{kg} / \mathrm{m})$ & 0.875 & 0.871 & 0.871 & 0.854 & 0.870 & $0.848-0.928$ \\
\hline \multicolumn{6}{|c|}{ 2. Yield Strength $\left(\mathrm{R}_{\mathrm{e}}\right) \mathrm{N} / \mathrm{mm}^{2}$} & $650>Y S>500$ \\
\hline Individual & 567.0 & 513.1 & 559.4 & 515.1 & 557.5 & \\
\hline Mean value $\bar{x}$ & \multicolumn{5}{|c|}{542.4} & \\
\hline Standard deviation [S] & \multicolumn{5}{|c|}{26.1} & \\
\hline $\bar{x}-\mathrm{ks} \quad(\mathrm{k}=1.53)$ & \multicolumn{5}{|c|}{502} & \\
\hline \multicolumn{6}{|c|}{ 3.Total elongation at maximum force $\left(\mathrm{A}_{\mathrm{gt}}\right) \%$} & $(>2.5)$ \\
\hline Individual & 4.33 & 8.92 & 6.43 & 7.00 & 4.73 & \\
\hline Mean value $\bar{x}$ & \multicolumn{5}{|c|}{6.28} & \\
\hline Standard deviation [s] & \multicolumn{5}{|c|}{1.85} & \\
\hline $\bar{x}-\mathrm{ks} \quad(\mathrm{k}=1.53)$ & \multicolumn{5}{|c|}{3.4} & \\
\hline 4. Stress Ratio $\left(\mathrm{R}_{\mathrm{m}} / \mathrm{R}_{\mathrm{e}}\right)$ & 1.19 & 1.26 & 1.19 & 1.18 & 1.20 & $(>1.05)$ \\
\hline
\end{tabular}

Source: Report No. MT/2858/2013

Materials Testing Laboratory of SLSI

Selecting the best composition of ingredients in the melt is one of the huge challenges faced by the scrap recycling industry. For enhanced quality in steel bars, correct metallurgy of the melt is required. Carbon Equivalent (CE) is increasingly drawing the attention of the steel making industry since it can have an effect on the properties like strength and weldability in steel bars. [4]

The aim of this research was to determine the optimum range of Carbon Equivalent value and the best mixed proportion of alloying chemicals that can lower the variation in yield strength and elongation of TMT bars in a set.

\section{Literature Review}

In steel making, scraps have to be selected carefully. Copper and tin are the most harmful contaminants found in scrap steel. Both metals contribute to a weakness known as 'hotshortness' which causes the steel to split during hot rolling. Since sulphur and phosphorus are major impurities which affect the mechanical properties of steels bars, most of the industry standards stipulate maximum allowable limits for these two elements. [1]

Residual elements like $\mathrm{Cu}, \mathrm{Ni}, \mathrm{Sn}, \mathrm{As}, \mathrm{Cr}, \mathrm{Mo}$, $\mathrm{Pb}$ etc., in steel cannot be removed using simple metallurgical processes as they have not been added intentionally. A major problem faced in improving the quality of steel is in controlling the level of residual elements in it. Residual elements influence processing from the beginning of casting to final heat treatment. Surface defects, interface segregation, grain boundary embrittlement and changes in hot strip properties are some of the deleterious effects caused by the presence of residuals in steel. [1]

Silicon (Si) in the form of ferro-silicon is added to liquid steel mainly as a de-oxidizer. It removes the undesirable oxygen dissolved in molten steel (Equation (1)). Manganese (Mn) can also be used to remove unwanted oxygen in the melt (Equation (2)). De-oxidation by $\mathrm{Si}$ is however more effective than that by Mn.

$\mathrm{Si}+2 \mathrm{O}=\mathrm{SiO}_{2}$

$\mathrm{Mn}+\mathrm{O}=\mathrm{MnO}$

Manganese is added to liquid steel specially to control its sulphur content. It combines more readily with residual sulphur, to form manganese-sulphide (MnS) (Equation (3)).

$\mathrm{Mn}+\mathrm{S}=\mathrm{MnS}$

This will reduce the formation of iron-sulphide (FeS), which is a brittle compound that lowers the toughness and ductility of steel and causes hot shortness in it.

Solid solution strengthening is a type of alloying that can be used to improve the strength of a pure metal. Depending on the size of the alloying element used, a substitutional solid solution or an interstitial solid solution can form. Carbon in iron (steel) is one example of interstitial solid solution. Manganese, a metallic alloying element with much larger atoms than carbon, (closer in size to those of iron) forms a substitutional solid solution when added by displacing iron atoms. Manganese blocks the mechanical movements of the iron lattices and thereby improves the strength and hardness of steel. Silicon can also cause a substitutional solid solution to form by occupying iron lattices. Silicon increases the strength and the hardness of steel although less effective in this regard than manganese. [15]

Compared to $\mathrm{Cr}$, both $\mathrm{Si}$ and $\mathrm{Mn}$ have a relatively potent effect on the hardness of ferrite. $\mathrm{Cr}$ increases the hardness only very slightly. $\mathrm{Cr}$, however, is the most convenient alloying element for steel that is processed by cold working for which good hardenability is required. Figure 1 shows how the hardness in ferrite is increased by substitutional solid solutions. 


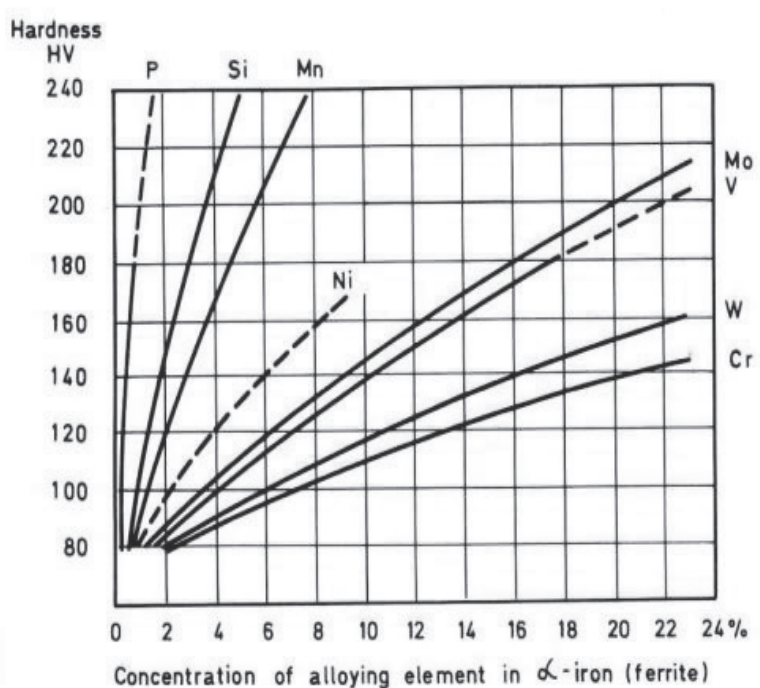

Figure 1 - Effect of substitutional alloying element additions on ferrite hardness [17].

Table 2 presents a comparison of the properties of the main alloying elements.

Table 2 - Comparison of $\mathrm{Mn}$ and Si used in the steel making process

\begin{tabular}{|c|c|}
\hline Manganese (Mn) & Sil \\
\hline An austenite stabilizer & A ferrite stabilizer \\
\hline $\begin{array}{l}\text { Lowers the eutectoid } \\
\text { transformation } \\
\text { temperature and the } \\
\text { eutectoid carbon content }\end{array}$ & $\begin{array}{l}\text { Raises the eutectoid } \\
\text { transformation } \\
\text { temperature, but } \\
\text { lowers the eutectoid } \\
\text { carbon content }\end{array}$ \\
\hline $\begin{array}{l}\text { Cubic structure (bcc). } \\
\text { Atomic Radius is } 0.112 \\
\mathrm{~nm} \\
\text { Vanderwaal Radius is } \\
0.126 \mathrm{~nm}\end{array}$ & $\begin{array}{l}\text { Diamond cubic } \\
\text { structure. } \\
\text { Atomic Radius is } 0.117 \\
\mathrm{~nm} \\
\text { Vanderwaal Radius is } \\
0.132 \mathrm{~nm}\end{array}$ \\
\hline $\begin{array}{l}\text { Forms a substitutional } \\
\text { solid solution in Fe } \\
\text { lattice }\end{array}$ & $\begin{array}{l}\text { Forms a substitutional } \\
\text { solid solution in Fe } \\
\text { lattice. }\end{array}$ \\
\hline $\begin{array}{l}\text { Highly effective in } \\
\text { strengthening steel. } \\
0.1 \% \text { addition of } \mathrm{Mn} \text { to } \\
\text { iron will increase the } \\
\text { yield strength by } 3 \mathrm{MPa}\end{array}$ & $\begin{array}{l}\text { Moderately effective in } \\
\text { strengthening steel. } \\
\text { Enhances the electrical } \\
\text { and magnetic } \\
\text { properties }\end{array}$ \\
\hline
\end{tabular}

Many countries have published standard specifications for ribbed steel bars to ensure their quality when used in their intended purposes. In Sri Lanka, SLS 375: 2009 (Specification for ribbed steel bars for the reinforcement of concrete) ensures the quality of ribbed steel bars when used as reinforcements in concrete. [4]

As per SLS 375: 2009 standard, the chemical composition of ribbed steel bars, based on its product analysis shall be in accordance with the figures given in Table 3.
Table 3 - Chemical composition of ribbed steel bars (maximum $\%$ by mass)

\begin{tabular}{|l|c|c|c|c|c|c|}
\hline & $\mathrm{C}$ & $\mathrm{S}$ & $\mathrm{P}$ & $\mathrm{N}$ & $\mathrm{Cu}$ & ${ }^{*} \mathrm{CE}$ \\
\hline $\begin{array}{l}\text { Cast } \\
\text { analysis }\end{array}$ & 0.22 & 0.05 & 0.05 & 0.012 & 0.80 & 0.50 \\
\hline $\begin{array}{l}\text { Product } \\
\text { analysis }\end{array}$ & 0.24 & 0.055 & 0.055 & 0.014 & 0.85 & 0.52 \\
\hline
\end{tabular}

Source: SLS 375: 2009 - Specification for ribbed steel bars for the reinforcement of concrete

$$
\begin{aligned}
\mathrm{CE}= & \% \mathrm{C}+\% \mathrm{Mn} / 6+(\% \mathrm{Cr}+\% \mathrm{Mo}+\% \mathrm{~V}) / 5 \\
& +(\% \mathrm{Ni}+\% \mathrm{Cu}) / 15
\end{aligned}
$$

Carbon Equivalent (CE) value is used to understand how the residuals and different alloying elements affect the strength of steel. Table 4 presents the contribution made by Carbon Equivalent value to the weldability of TMT bars. [4]

Table 4 - Weldability of TMT bars based on CE values

\begin{tabular}{|l|l|}
\hline $\begin{array}{l}\text { Carbon } \\
\text { Equivalent }(\mathrm{CE})\end{array}$ & Weldability of TMT bars \\
\hline Up to 0.35 & Excellent \\
\hline $0.36-0.40$ & Very good \\
\hline $0.41-0.45$ & Good \\
\hline $0.46-0.50$ & Fair \\
\hline Over 0.50 & Poor \\
\hline
\end{tabular}

Source: Technical Report 1967, IIW Doc. IX-535-67

\section{Experimental Procedure}

In the experimental work, the mixing quantities of the main alloying chemicals were changed to ensure that the diluted percentage of the manganese content in the liquid solution was $0.8 \%$ by mass. A mix-proportion of ferro-silicon and ferro-silico-manganese which was determined considering product specifications and past experience in trial mixes was added to a number of charges during the melting process.

Seventy kilograms of ferro-silico-manganese (Mn:60\% and Si:14\% by mass) were added to the melt of 5 metric tons. The quantities of manganese and silicon added were $42 \mathrm{~kg}$ and $9.8 \mathrm{~kg}$ respectively. Additionally, $2 \mathrm{~kg}$ of ferrosilicon (Si: $70 \%$ by mass) were added to the melt just before tapping, and $1.4 \mathrm{~kg}$ of silicon obtained. The total amount of silicon added to the melt was $11.2 \mathrm{~kg}$. The mixed proportion of silicon to manganese in the melt initially was 1 is to 4 approximately. 


\subsection{Sampling}

Before rolling the prepared ingots into bars, ingot samples were collected from 19 different charges/ batches for chemical analysis.

After manufacturing $10 \mathrm{~mm}$ TMT bars using the ingots of the identified charge numbers, a set of TMT bar samples was taken for testing their yield strengths and elongations. All TMT bars were manufactured by optimally controlling the water quenching process parameters.

\subsection{Testing}

Chemical analysis of the ingot samples was carried out using the Spectro Spark Analyzer that was available at the steel plant. Because of its rapid analysis time and inherent accuracy, the Spectro Spark Analyzer is more effective in controlling the processing of alloys and residuals. The data used in this study for the spectrometer analysis are given in Appendix 01.

Tensile testing of the TMT bar samples was carried out using the Universal Testing Machine (UTM) that was also available at the steel plant. All the specimens were tested without any machining and in accordance with the SLS 375: 2009 standard. The test data obtained are given in detail in Appendix 02.

\subsection{Analysis of Test Data}

The test results of nineteen charges were analysed using Matlab and Microsoft Excel, to assess the standard deviations of yield strength, for the mixed proportions given in Table 5.

A statistical analysis in terms of $R^{2}$ values was conducted using Minitab to identify the curves that best fit the data (CE versus STD-YS and CE versus STD-Elongation), as shown in Figure 2 and Figure 3 respectively.

\section{Results and Discussion}

\subsection{Mixed Proportion of Alloying Chemicals}

For the mixed proportions of $\mathrm{Si}$ to $\mathrm{Mn}$ given in Table 5, a very low value for the standard deviation of yield strength (STD-YS < 10) was observed with ferro-silicon and ferro-silicomanganese mixed at the proportion of $1: 4$ ( $\mathrm{Si}$ : $\mathrm{Mn}$ ) approximately.
It was also observed that STD-YS changes when the mixed proportion is changed.

Table 5 - Analysis of the mixed proportions of Si to Mn

\begin{tabular}{|r|c|c|c|c|r|r|}
\hline$\#$ & C & Mn & Si & YS & $\begin{array}{c}\text { STD- } \\
\text { YS }\end{array}$ & Mn/ Si \\
\hline 1 & 0.177 & 0.725 & 0.161 & 559.30 & 10.41 & 4.5 \\
\hline 2 & 0.196 & 0.793 & 0.213 & 552.38 & 8.34 & 3.7 \\
\hline 3 & 0.169 & 0.817 & 0.177 & 549.15 & 13.82 & 4.6 \\
\hline 4 & 0.192 & 0.725 & 0.210 & 561.61 & 7.43 & 3.5 \\
\hline 5 & 0.190 & 0.919 & 0.214 & 551.27 & 14.28 & 4.3 \\
\hline 6 & 0.193 & 0.854 & 0.219 & 560.99 & 7.07 & 3.9 \\
\hline 7 & 0.186 & 0.845 & 0.178 & 547.40 & 10.09 & 4.7 \\
\hline 8 & 0.189 & 0.814 & 0.221 & 522.59 & 6.17 & 3.7 \\
\hline 9 & 0.183 & 0.821 & 0.209 & 509.54 & 6.33 & 3.9 \\
\hline 10 & 0.200 & 0.844 & 0.172 & 522.30 & 16.62 & 4.9 \\
\hline 11 & 0.179 & 0.826 & 0.196 & 536.37 & 7.26 & 4.2 \\
\hline 12 & 0.196 & 0.910 & 0.144 & 558.73 & 10.95 & 6.3 \\
\hline 13 & 0.196 & 0.847 & 0.205 & 546.12 & 12.42 & 4.1 \\
\hline 14 & 0.198 & 0.915 & 0.189 & 541.23 & 11.43 & 4.8 \\
\hline 15 & 0.202 & 0.759 & 0.207 & 527.27 & 7.77 & 3.7 \\
\hline 16 & 0.185 & 0.751 & 0.197 & 527.18 & 11.47 & 3.8 \\
\hline 17 & 0.201 & 0.798 & 0.218 & 516.39 & 6.67 & 3.7 \\
\hline 18 & 0.189 & 0.822 & 0.196 & 562.52 & 7.54 & 4.2 \\
\hline 19 & 0.201 & 0.872 & 0.187 & 522.28 & 15.32 & 4.7 \\
\hline
\end{tabular}

De-oxidation is one of the most important stages in steel making. The steel bath at the time of tapping contains 400 to $800 \mathrm{ppm}$ activity of oxygen. De-oxidation is carried out during tapping by adding appropriate amounts of ferro alloys or special de-oxidizers to the steel. Ferro-silico-manganese is added as a desulphurizing agent as well as a de-oxidizer. Ferro-silicon is mainly a de-oxidizer of molten steel. De-oxidation by $\mathrm{Si}$ is more complete than that by $\mathrm{Mn}$, and simultaneous de-oxidation by these two elements gives rise to a lower residual oxygen content in the bath solution. Depending on the concentration of $\mathrm{Si}$ and $\mathrm{Mn}$ added to the molten steel, de-oxidation product will be either in molten manganese silicate $\left(\mathrm{MnO} . \mathrm{SiO}_{2}\right)$ or solid silica $\left(\mathrm{SiO}_{2}\right)$. In addition to its use in the production of steel ingots to eliminate blowholes, de-oxidation is also employed for grain size controlling that will enhance the strength and toughness of steel.

Manganese (Mn) is the most prevalent alloying agent in steel, second to carbon (C). The increase in the strength and hardenability of steel obtained by using $\mathrm{Mn}$ is somewhat less than that obtained by using C. Mn improves hot workability of steel by preventing the formation of low melting iron sulphide (FeS). Another important feature of Mn is its ability to stabilize the austenite content in steel. Mn helps 
to lower the temperature at which austenite transforms into ferrite, thus avoiding cementite precipitation at ferrite grain boundaries. Mn addition promotes finer grain sizes to strengthen the steel. There is no satisfactory substitute for $\mathrm{Mn}$ in the steel making industry given its relatively low cost and outstanding technical benefits.

Silicon ( $\mathrm{Si}$ ) is used mainly as a de-oxidizer in the steel making process. It slightly increases the strength of ferrite, and when used in conjunction with manganese can help to increase the strength and toughness of steel.

The yield strength increase of steel will depend on the concentration of solute atoms in the iron lattices. However, the industry standards limit the maximum possible solubility of alloying elements, in order to prevent the formation of hard and brittle phases.

Manganese content cannot be increased unduly, as it can become harmful. $\mathrm{Mn}$ is specified in low carbon steels in the range up to $1 \%$ by mass. A high manganese content will increase the formation of martensite in steel and thereby its hardness and will also raise its ductile to brittle transition temperature. Increased amounts of de-oxidizers that are stronger than $\mathrm{Mn}$ such as silicon ( $\mathrm{Si}$ ) or aluminium (Al) can cause Mn to transfer from slag to metal. A high content of Si in low carbon steels is detrimental to surface quality. Therefore, the most appropriate mixed proportion of the alloying chemicals that can be used in the secondary steel making process has to be decided carefully to avoid these undesirable effects.

According to the results of the experimental study, very precise and accurate results on yield strength can be obtained by setting the mixed proportion of Si to Mn at approximately 1 is to 4 .

\subsection{Carbon Equivalent (CE) for Improved Quality}

A graphical analysis was carried out to see how the $C E$ value can be controlled to reduce the standard deviations of yield strength and longation, while preserving weldability of TMT bars.
In the two graphs given in Figure 2 and Figure 3 , standard parameters $S$ (standard error of the regression), $\mathrm{R}^{2}$ (coefficient of determination) and 'adjusted $\mathrm{R}^{2}$ ' are used to explain how well the model fits the data set. $\mathrm{S}$ which is measured in the same units as the response variable represents the average distance that the data values fall from the regression line/ curve. Smaller $S$ values are better because then the observations will be closer to the fitted line. $\mathrm{R}^{2}$ value gives the proportion of variance in the dependent variable that can be explained by the independent variables. The predictions are much more precise at high $\mathrm{R}^{2}$ values. Low $\mathrm{R}^{2}$ values will be problematic when precise predictions are needed.

In the curve of "CE vs. STD-YS" given in Figure 2 , most of the standard deviations of the yield strength were observed to be quite low for $\mathrm{CE}$ values falling in the range $0.37<\mathrm{CE}<0.4 \%$ by mass. Outside this range, the yield strengths are found to vary very much.

This implies that, within that given range of $\mathrm{CE}$ values, each and every bar in the lot would have a uniform yield strength, with the variation among the bars at a very low value. The most probable reason for this behaviour of the TMT bars could be the presence of an accurate concentration of $\mathrm{Mn}$ in the steel.

It is evident that, $\mathrm{C}$ and $\mathrm{Mn}$ are the main contributors for increasing the $\mathrm{CE}$ value when compared with the weightages of other residuals. The grain size refinement caused by the addition of Mn strengthens steel. The yield strength is increased as the grain size is reduced (ferrite, bainite, or pearlite). In addition, for a given $\mathrm{C}$ content the pearlite content will increase as the Mn concentration is increased with the yield strengths of the steel bars also increasing uniformly. 


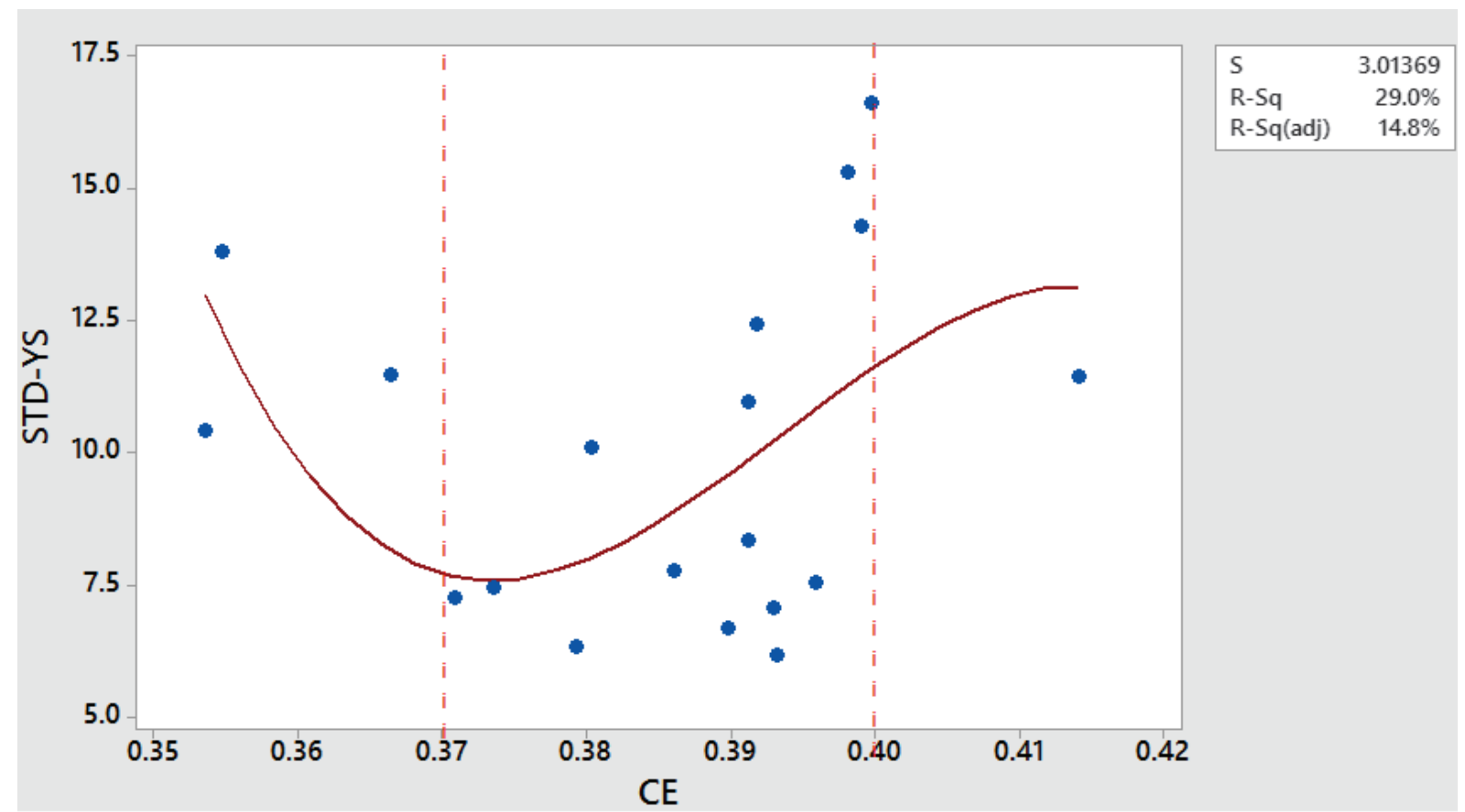

Figure 2 - Fitted line plot in cubic form (CE vs. STD-YS)

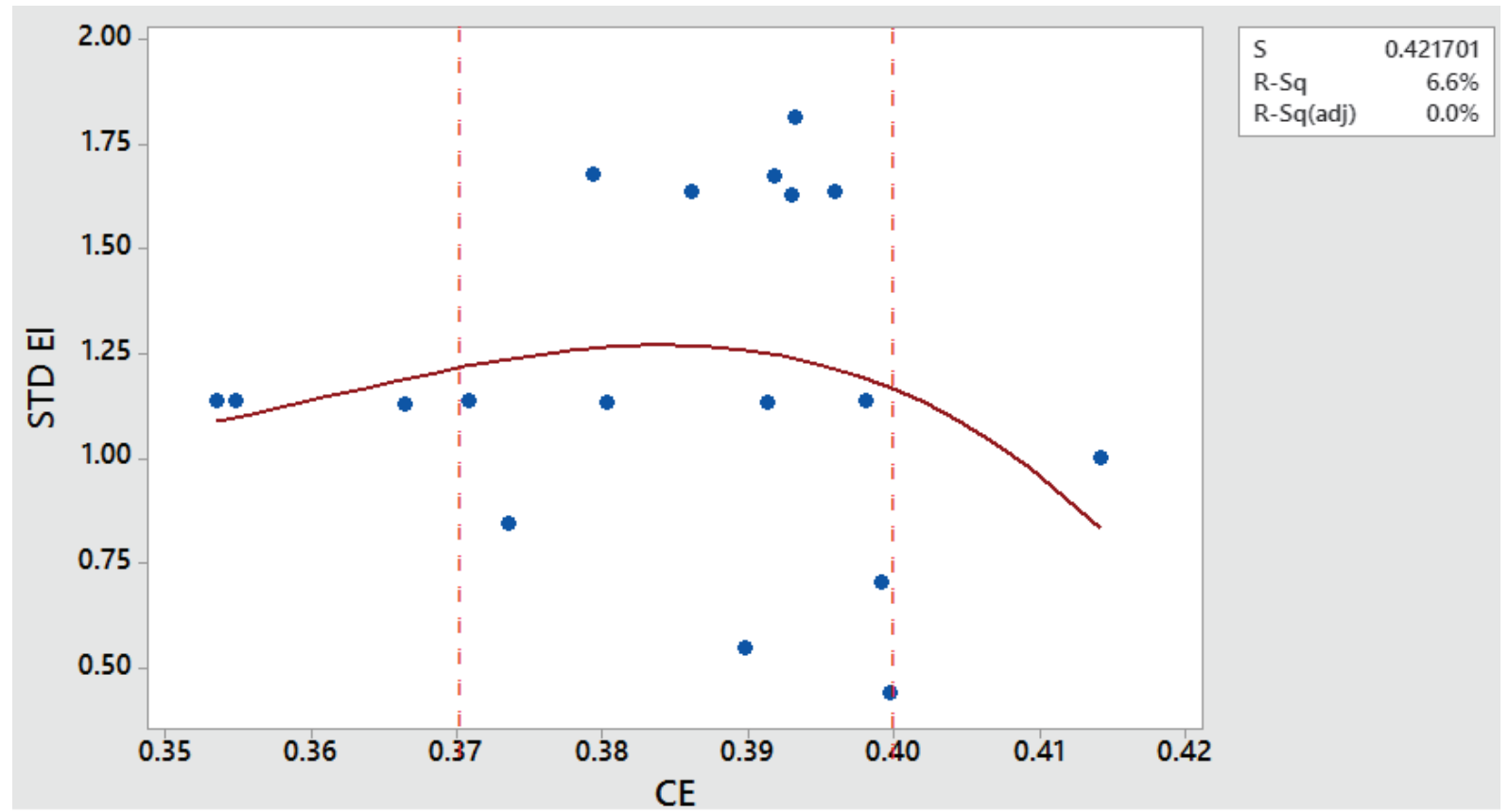

Figure 3 - Fitted line plot in cubic form (CE vs. STD- Elongation)

For the interpretation of data in Figure 2, $\mathrm{S}$ is 3.01369 units of STD-YS. Additionally, $29.0 \%$ of the variation in STD-YS is explained by CE.

For the interpretation of data in Figure 3, $\mathrm{S}$ is 0.421701 units of STD-El. Additionally, $6.6 \%$ of the variation in STD-El is explained by CE.

Unlike in the curve of "CE vs. STD-YS" plotted in Figure 2, in the "CE vs. STD-El" curve plotted in Figure 3, the range of CE values over which the standard deviation of elongation remains low is not significant. However, it was noted that the standard deviation of elongation (STD-El) is decreased (in a downward trend) as the $C E$ value is increased.

The higher the CE value, the higher will be the tendency for the strength of steel to increase. Then each TMT bar will gain strength and hardness equally. For this reason, the standard 
deviation of elongation of the individual bars decreases as the CE values are increased.

From the graphical analysis, it is revealed that consistent values of yield strength and elongation can be achieved (while preserving the weldability) for the set of TMT bars by having the Carbon Equivalent value in the range $0.37<\mathrm{CE}<0.4 \%$ by mass.

\section{Conclusions}

The mix-proportion of the main alloying chemicals, $\mathrm{Si}$ and $\mathrm{Mn}$, and the $\mathrm{CE}$ values are found to influence the yield strength and elongation of TMT bars causing high variations of these properties among the bars of a set. Therefore, precise controlling of alloy addition during de-oxidation and de-sulphurisation treatment of liquid steel in the ladle is necessary to obtain a low variation in yield strength and elongation of TMT bars.

Based on the results of the experimental study, the following conclusions can be drawn to ensure consistent quality in TMT bars:

1. Ferro-silicon (Si) and ferro-silicomanganese $(\mathrm{Mn})$ have to be added to the melt or liquid solution so that the mixproportion of $\mathrm{Si}: \mathrm{Mn}$ is $1: 4$ approximately.

2. Carbon Equivalent value in the melt or liquid solution has to be controlled to be in the range $0.37<\mathrm{CE}<0.4 \%$ by mass.

\section{References}

1. Herman, J. C., Leroy, V., "Influence of Residual Elements on Steel Processing and Mechanical Properties"; C.R.M. rue Ernest Solvay 11, 4000 Liege, Belgium.

2. IOSR Journal of Mechanical and Civil Engineering (IOSRJMCE), "Improvement in yield strength of deformed steel bars by quenching using Taguchi method" -, ISSN: 22781684 Vol. 2, Issue 2 (Sep-Oct 2012), PP 01-11 (http://www.iosrjournals.org)

3. ISO/TR 16078: 2013 (E/F) (First Edition), "Technical Report on the classification and designation systems for casting imperfections", International Organization for Standardization, Geneva, Switzerland.

4. SLS 375: 2009 (4th Revision), "Specifications for Ribbed Steel Bars for the reinforcement of concrete", Sri Lanka Standards Institution.

5. Malcolm S. Burton (Chapter 01), “Applied Metallurgy for Engineers", School of Chemical and Metallurgical Engineering, Cornell University.
6. ISRI - Scrap Specifications Circular 2012 "Guideline for Ferrous Scraps: FS-2012:, Guidelines for Nonferrous Scrap, Ferrous Scrap, Glass Cullet, Paper Stock, Plastic Scrap, Electronic Scrap, Tire Scrap", Institute of Scrap Recycling Industries, Inc. 1615 L St.N.W., Suite 600, Washington, DC 20036-5664. (http://www.isri.org)

7. Journal of Civil Engineering Research 2012- 2(1): 14-17, "Performance Enhancement of TMT Rebar in accelerated Corrosion", DOI: 10.5923/j.jce.20 120201.03, Department of Civil Engineering, NITK, Surathkal. Srinivasnagar, 575025, India

8. Edgar C. Bain, "Functions of the alloying elements in Steel" Am. Soc. Metals, Metals Park, Ohio (1939) 312 pages.

9. American Society for Metals, "Properties and Selection: Iron, Steels, and High-performance Alloys" Metals Handbook (1990) Vol.1 (10th edition), Am. Soc. Metals, Metals Park, Ohio.

10. Duggal, S. K., "Building Materials" (Fourth Edition), Civil Engineering Department, Motilal Nehru Institute of Technology, Allahabad (U.P.), India

11. BS 4449: 2005, "Hot rolled steel bars for the reinforcement of concrete", London: British Standards Institution.

12. Thomas G. Digger, Samuel J. Rosenberg and Glenn W. Geil, "Heat Treatment and Properties of Iron \& Steel", National Bureau of Standards, Monograph. 88', Nov. 1, 1966, (Washinton D C 20402)

13. SLS 978: 2004/ ISO 6892: 1998 (E) "Metallic Materials - Tensile Testing at Ambient Temperature", Sri Lanka Standards Institution.

14. Smarajit Sarkar, Presentation on "Advances in steelmaking and secondary steel making", Department of Metallurgical and Materials Engineering, NIT Rourkela

15. MSE 300, Materials Laboratory Procedures, "Fe-C liquid solution", Dept. of Materials Science and Engineering, University of Tennessee, USA

16. Lauri Ho Jappa and Seppo Louhenkilpi, "The role of ferroalloys in steelmaking", Department of Materials Science and Engineering, Aalto University School of Chemical Technology, Vuorirniehentie 2, PO Box 16200, FI-00076, Aalto, Finland.

17. Mehran Maalekian "The Effects of Alloying Elements on Steels", (published in October 2007), Christian Doppler Laboratory for Early Stages of Precipitation, The Graz University of Technology (TU Graz), Austria. 
Appendix 01 - Spectrometer analysis data (cast analysis) used in the study

\begin{tabular}{|c|c|c|c|c|c|c|c|c|c|c|c|c|}
\hline $\begin{array}{c}\text { Charge } \\
\#\end{array}$ & $\mathbf{C}$ & $\mathbf{M n}$ & $\mathbf{C r}$ & $\mathbf{M o}$ & $\mathbf{V}$ & $\mathbf{N i}$ & $\mathbf{C u}$ & $\mathbf{C E}$ & $\mathbf{S}$ & $\mathbf{P}$ & $\mathbf{S i}$ & $\mathbf{F e}$ \\
\hline 1 & 0.177 & 0.725 & 0.057 & 0.021 & 0.0061 & 0.059 & 0.525 & 0.35 & 0.014 & 0.029 & 0.161 & 98.089 \\
\hline 2 & 0.196 & 0.793 & 0.069 & 0.021 & 0.0036 & 0.051 & 0.615 & 0.39 & 0.021 & 0.023 & 0.213 & 97.904 \\
\hline 3 & 0.169 & 0.817 & 0.061 & 0.026 & 0.0021 & 0.057 & 0.420 & 0.35 & 0.019 & 0.017 & 0.177 & 98.092 \\
\hline 4 & 0.192 & 0.725 & 0.057 & 0.021 & 0.0060 & 0.059 & 0.600 & 0.37 & 0.014 & 0.029 & 0.210 & 97.999 \\
\hline 5 & 0.190 & 0.919 & 0.063 & 0.023 & 0.0047 & 0.047 & 0.520 & 0.40 & 0.016 & 0.015 & 0.214 & 97.909 \\
\hline 6 & 0.193 & 0.854 & 0.043 & 0.021 & 0.0023 & 0.056 & 0.610 & 0.39 & 0.029 & 0.021 & 0.219 & 98.065 \\
\hline 7 & 0.186 & 0.845 & 0.047 & 0.018 & 0.0057 & 0.026 & 0.565 & 0.38 & 0.021 & 0.019 & 0.178 & 97.998 \\
\hline 8 & 0.189 & 0.814 & 0.088 & 0.026 & 0.006 & 0.073 & 0.595 & 0.39 & 0.017 & 0.025 & 0.221 & 97.854 \\
\hline 9 & 0.183 & 0.821 & 0.087 & 0.025 & 0.0059 & 0.064 & 0.475 & 0.38 & 0.028 & 0.029 & 0.209 & 97.968 \\
\hline 10 & 0.200 & 0.844 & 0.058 & 0.024 & 0.0054 & 0.079 & 0.545 & 0.40 & 0.015 & 0.028 & 0.172 & 97.886 \\
\hline 11 & 0.179 & 0.826 & 0.078 & 0.014 & 0.0077 & 0.059 & 0.455 & 0.37 & 0.017 & 0.021 & 0.196 & 98.021 \\
\hline 12 & 0.196 & 0.910 & 0.014 & 0.016 & 0.0072 & 0.073 & 0.470 & 0.39 & 0.017 & 0.026 & 0.144 & 98.019 \\
\hline 13 & 0.196 & 0.847 & 0.071 & 0.036 & 0.0071 & 0.088 & 0.390 & 0.39 & 0.028 & 0.028 & 0.205 & 98 \\
\hline 14 & 0.198 & 0.915 & 0.076 & 0.025 & 0.0052 & 0.087 & 0.550 & 0.41 & 0.027 & 0.032 & 0.189 & 97.79 \\
\hline 15 & 0.202 & 0.759 & 0.076 & 0.025 & 0.0055 & 0.090 & 0.455 & 0.39 & 0.029 & 0.032 & 0.207 & 97.994 \\
\hline 16 & 0.185 & 0.751 & 0.057 & 0.029 & 0.053 & 0.072 & 0.355 & 0.37 & 0.014 & 0.028 & 0.197 & 98.141 \\
\hline 17 & 0.201 & 0.798 & 0.061 & 0.023 & 0.0078 & 0.072 & 0.490 & 0.39 & 0.022 & 0.026 & 0.218 & 97.976 \\
\hline 18 & 0.189 & 0.822 & 0.083 & 0.032 & 0.0077 & 0.086 & 0.595 & 0.40 & 0.03 & 0.023 & 0.196 & 97.825 \\
\hline 19 & 0.201 & 0.872 & 0.071 & 0.026 & 0.0074 & 0.084 & 0.380 & 0.40 & 0.03 & 0.025 & 0.187 & 98.026 \\
\hline
\end{tabular}

$\mathrm{CE}=\% \mathrm{C}+\% \mathrm{Mn} / 6+(\% \mathrm{Cr}+\% \mathrm{Mo}+\% \mathrm{~V}) / 5+(\% \mathrm{Ni}+\% \mathrm{Cu}) / 15$

\section{Appendix 02 - Test data of the tensile properties (10 mm TMT bars)}

\begin{tabular}{|c|c|c|c|c|c|c|c|c|c|c|c|c|c|c|c|c|}
\hline \multirow{4}{*}{ 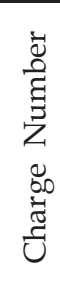 } & \multicolumn{16}{|c|}{ Tensile Properties } \\
\hline & \multicolumn{8}{|c|}{ Yield Strength $\left(\mathrm{N} / \mathrm{mm}^{2}\right)$} & \multicolumn{8}{|c|}{ Total Elongation at max force (\%) } \\
\hline & \multicolumn{5}{|c|}{ Individuals } & \multirow{2}{*}{ 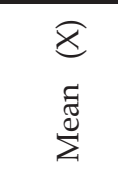 } & \multirow{2}{*}{ 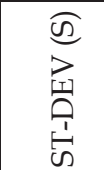 } & \multirow{2}{*}{ 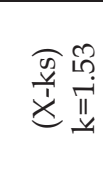 } & \multicolumn{5}{|c|}{ Individuals } & \multirow{2}{*}{$\begin{array}{l}\bar{z} \\
\approx \\
\tilde{\Xi}^{2}\end{array}$} & \multirow{2}{*}{ 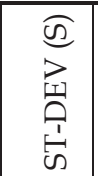 } & \multirow{2}{*}{ 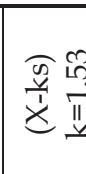 } \\
\hline & 1 & 2 & 3 & 4 & 5 & & & & 1 & 2 & 3 & 4 & 5 & & & \\
\hline 1 & 559.96 & 76.29 & 9.82 & 32.22 & 4 & 574.91 & 10.41 & 9.30 & 7.31 & 31 & 5.32 & 4.31 & 5.33 & 5.72 & 1.14 & 4.01 \\
\hline 2 & 555.67 & 68.4 & 566.10 & 557.91 & 5 & 564.89 & 8.34 & 552.38 & 4.37 & 6.33 & 3.34 & 33 & 5.33 & 4.74 & 13 & 3.04 \\
\hline 3 & $\begin{array}{l}558.81 \\
\end{array}$ & 559.0 & 565.62 & 591.99 & 573.93 & 569.87 & 13.82 & 549.15 & $\begin{array}{l}7.34 \\
\end{array}$ & 6.33 & 5.34 & 33 & 4.35 & 5.74 & .14 & 4.03 \\
\hline 4 & 584.03 & 574. & 570.79 & 570. & & 572.75 & 7.43 & 561.61 & 5.32 & 6.34 & 4.34 & 5.34 & 4.31 & 5.13 & 84 & 3.87 \\
\hline 5 & 581.58 & 547. & 578.11 & 579 & 5 & 572.69 & 14.28 & 551.27 & 4.3 & 4.32 & 3.33 & 5.32 & 4.31 & 4.32 & 70 & 3.27 \\
\hline 6 & 569.71 & 575.2 & 580.53 & 571. & 5 & 571.59 & 7.07 & 560.99 & 4.3 & 5.31 & 4. & 8.30 & 5.34 & 5.52 & .63 & 3.08 \\
\hline 7 & 568.20 & \begin{tabular}{|l}
544. \\
\end{tabular} & 569.39 & 563.9 & 566 & 562.53 & 10.09 & 547.40 & 7.32 & 5.33 & 6.33 & 32 & 7.32 & 6.92 & 14 & 5.22 \\
\hline 8 & 532.69 & \begin{tabular}{|l|}
539.85 \\
\end{tabular} & 527.35 & 524.29 & 535.01 & 531.84 & 6.17 & 522.59 & 5.31 & 8.31 & 5.31 & 9.31 & 6.32 & 6.91 & 1.82 & 4.19 \\
\hline 9 & 526.39 & \begin{tabular}{|l|}
518.9 \\
\end{tabular} & 522.54 & 509.40 & 517.93 & 519.04 & 6.33 & 509.54 & 6.31 & 8.32 & 6.30 & 4.31 & 8.33 & 6.71 & 68 & 4.19 \\
\hline 10 & & & & & & 547.22 & 2 & 522.30 & & 6.32 & & & 5.33 & 6.12 & 4 & 5.46 \\
\hline 11 & 54 & 540 & 4 & 540 & $55 ?$ & 547.25 & 77 & 536.37 & 7.3 & 6.31 & & $\pi$ & 4.31 & 5.71 & 4 & 4.00 \\
\hline 12 & 585.31 & \begin{tabular}{|l}
582.50 \\
\end{tabular} & 581.11 & 561.13 & 565.67 & 575.14 & 0.95 & 558.73 & 6.32 & 5.33 & 7.33 & 8.31 & 6.31 & 6.72 & 14 & 5.02 \\
\hline 13 & 569.51 & \begin{tabular}{|l|}
579.01 \\
\end{tabular} & 565.40 & 564.87 & 544.98 & 564.75 & 12.42 & 546.12 & 6.32 & 4.31 & & 6.32 & 8.31 & 5.91 & 67 & 3.40 \\
\hline 14 & 567.12 & \begin{tabular}{|l}
544.80 \\
\end{tabular} & 548.95 & 559.52 & 571.47 & 558.37 & 11.43 & 541.23 & 5.32 & 6.33 & 4.32 & 4.32 & 6.31 & 5.32 & 00 & 3.82 \\
\hline 15 & 551.62 & 533.99 & 541.04 & 535.27 & 532 & 538.93 & 7.77 & 527.27 & 6.3 & 5.30 & 8.30 & 8.3 & 9.29 & 7.50 & 1.64 & 5.05 \\
\hline 16 & & & 537.74 & 553 & & 544.39 & 11.47 & 527.18 & 7.2 & 6.29 & & & 5.30 & 5.69 & & 4.00 \\
\hline 17 & 53 & \begin{tabular}{|l}
524. \\
\end{tabular} & 522.53 & & & & 6.8 & 516 & & & 5 & 27 & 5.28 & 5.88 & & 5.06 \\
\hline 18 & 573.34 & \begin{tabular}{|l|}
570.80 \\
\end{tabular} & 576.72 & 584.36 & 563.90 & 573.82 & 7.54 & 562.52 & 6.32 & 5.32 & 8.32 & 8.31 & 9.31 & 7.52 & .64 & 5.06 \\
\hline 19 & 527.41 & 553.45 & 537.74 & 540.65 & 567.07 & 545.26 & 15.32 & 522.28 & 7.3 & 6.31 & 5.3 & 5.31 & 4.31 & 5.71 & 1.14 & 4.00 \\
\hline \multicolumn{9}{|c|}{$500<$ Yield Stress $<650$} & \multicolumn{8}{|c|}{$2.5<$} \\
\hline
\end{tabular}

